\title{
Televisão e novas mídias: repensando o papel das audiências nos telejornais
}

\section{Beatriz Becker}

\section{Resumo}

Este artigo busca identificar as interações entre a televisão e a internet no ambiente midiático onde o Jornal Nacional está inserido, verificar as atuais caracteríticas de linguagem das narrativas jornalísticas audiovisuais e compreender como as relações com os públicos são estabelecidas na experiência da cultura participativa incrementada pela convergência, a partir da análise televisual da cobertura dos Protestos de Junho do noticiário de maior audiência do país. É amparado nas contribuições das teorias da comunicação e dos estudos de jornalismo e de recepção.

\section{Palavras-Chave}

Televisão. Telejornalismo. Internet. Audiências. Jornal Nacional.
Beatriz Becker I beatrizbecker@uol.com.br Doutora em Comunicação e Cultura pela Universidade Federal do Rio de Janeiro (UFRJ) com Pós-Doutorado realizado no Programa de Estudos Pós-Graduados em Comunicação e Semiótica da Pontifícia Universidade Católica de São Paulo (PUC-SP). Professora Associada do Programa de Pós-Graduação e do Departamento de Expressões e Linguagens da Escola de Comunicação da Universidade Federal do Rio de Janeiro (PPGCOM/ECO-UFRJ) e bolsista de Produtividade do CNPq.

\section{Introdução}

A atual fase da televisão é marcada por um novo tipo de consumo televisivo, caracterizado por uma recepção fragmentada, na qual os telespectadores/ usuários assistem a um programa diferente em cada tela na mesma hora com possibilidade de comporem suas próprias grades de programação (MACHADO, 2011; SCOLARI, 2009; VILCHES, 2009). A maneira como passamos a assistir a TV também provoca desdobramentos no mercado porque provedores de conteúdos on demand entregues via IP disputam a atenção das audiências, o que tende a transformar o valor do break comercial, a estrutura vertical da programação das emissoras e a própria noção de fluxo televisual. As redes tradicionais não definem mais sozinhas os conteúdos que passam a ser vistos e distribuídos. E observa-se nos processos de digitalização da tevê e dos meios a aparição de pequenos produtores de conteúdos audiovisuais para diferentes tipos de mídia. 0 ciclo de realimentação de vídeos entre a televisão e a internet na construção de notícias corresponde a uma das características mais inovadoras dos acontecimentos midiáticos. A especificidade da TV já não se encontra 
agora na extensão linear das histórias, mas numa expansão em diferentes meios com uma mistura cada vez maior de gêneros informativos e ficcionais. A incorporação de diferentes linguagens e suportes na maneira de trabalhar as informações introduz distintas possibilidades de armazenamento, distribuição e consumo de notícias. Os conteúdos e formatos noticiosos em áudio e vídeo têm sido construídos em ambientes e linguagens híbridos. A maior parte dos relatos jornalísticos disponibilizada na televisão e na internet ainda mantém a estrutura narrativa dos noticiários, mas sofre influências de ambos os meios, nomeados como práticas de jornalismo audiovisual (BECKER, 2009). Os efeitos da convergência já incidem sobre a linguagem dos telejornais. Esses textos noticiosos podem ser acessados por meio de uma variedade de dispositivos e plataformas em diferentes telas (RODRÍGUEZ; DÍAZ-GONZÁLEZ; TORRE, 2013). 0 público pode fazer comentários, compartilhar mensagens, interagir com vídeos como fonte de consulta e participar como colaborador na produção de notícias. Além disso, registros de fatos que ocorrem fora dos canais de televisão convencionais via internet em streaming - uma forma de distribuição de informações audiovisuais por meio do uso das ferramentas digitais, cujos dados nem sempre podem ser arquivados - impõem mudanças ainda mais expressivas ao modelo tradicional dos noticiários televisivos. Porém, a produção colaborativa em áudio e vídeo em coberturas telejornalísticas não resulta em relatos mais contextualizados dos acontecimentos e em maior inventividade estética, uma vez que as tecnologias digitais disponíveis não são em si suficientes para garantir a qualidade e a diversidade do jornalismo audiovisual (BECKER, 2012a). As apropriações das tecnologias digitais não quebram o poder dos grandes grupos de mídia.

A TV atinge quase todo o território nacional e ainda se consolida no país como a principal fonte de informação e entretenimento para a maioria da população. Na grade de programação das emissoras de televisão aberta os telejornais ocupam lugares estratégicos porque constroem a experiência da vida social, vendem credibilidade e atraem recursos financeiros; assim, concentram os maiores valores de investimentos publicitários em seus breaks comerciais. 0 Jornal Nacional (JN) é o telejornal de maior audiência no país, com uma média de 35 pontos do Ibope, o que equivale dizer que a cada 100 aparelhos ligados, 35 estão conectados neste telejornal. (REDE GLOB0, [2007]) Para veicular um anúncio de 30" no JN no horário nobre na maior emissora de televisão aberta do Brasil, a Rede Globo, os anunciantes precisam desembolsar $\mathrm{R} \$$ 593.300,00, o maior custo de inserção publicitária da programação. ${ }^{1} \mathrm{~A}$ televisão brasileira reuniu de novembro de 2012 a novembro de 2013 mais de 60\% dos investimentos publicitários no Brasil, um total de 19,3 bilhões de reais, enquanto nenhuma outra mídia chegou a acumular 10\% desses 
recursos no mesmo período. ${ }^{2}$ esse contexto, os telejornais ainda configuram-se como os produtos de informação de maior impacto na sociedade e exercem uma centralidade nos discursos midiáticos contemporâneos (BECKER, 2005).

Porém, a televisão não pode ser mais compreendida apenas como um meio massivo por interagir com diversos suportes e linguagens midiáticos e distintas apropriações de seus conteúdos e formatos em áudio e vídeo. Em vez de anunciar-se a irrelevância do conceito de massa na contemporaneidade, considera-se mais produtivo discutir como a indústria de comunicação e suas audiências atualizam-se (PRIM0, 2013) e hoje intervêm nas práticas jornalísticas audiovisuais. Nesse sentido, torna-se relevante compreender as reconfigurações do jornalismo audiovisual, observando os modos como as notícias televisivas são produzidas, circulam e são consumidas pelas audiências. Este artigo propõe uma reflexão sobre a expansão da TV e do telejornalismo no ambiente midiático, a partir da análise televisual da cobertura dos Protestos de junho de 2013 no país ${ }^{3}$ realizada pelo JN. Observamse as características das notícias e as relações estabelecidas com diferentes públicos, o que demanda um pensamento crítico sobre o esquema clássico dos processos de comunicação baseados na tríade formada pelo emissor, a mensagem e 0 receptor para a expressão das referências teóricas deste trabalho.

\section{Audiências e teorias da comunicação}

Em uma obra polifônica o diálogo pressupõe um grupo de homens cujas vozes ressoam em igualdade de poder, sem que uma domine a outra (BAKHTIN, 2002). Compreende-se que 0 dialogismo em Bakhtin é o princípio constitutivo da linguagem e a polifonia discursiva implica confrontos entre discursos sociais mais amplos, por meios dos quais são expresssas as contradições de uma época. Machado (2006) sugere que 0 sistema polifônico invocado por Bakhtin representa a imprevisibilidade e a relatividade de eventos e modelos diante da diversidade de pontos de referência no plano ideológico. No entanto, ressalta que 0 dialogismo de Bakhtin e toda a investigação literária não dão conta do receptor porque esse dialogismo é visto dentro da obra, no embate entre personagens, ou no conflito entre o texto e 0 autor. Se a contribuição do pensamento literário não consegue superar a unilateralidade

Dados disponíveis em: <http://www.projetointermeios.com.br/relatorios/rel_investimento_5_0.pdf>.Acesso em: 17 fev. 2014.

Centenas de manifestantes convocados pelo Movimento Passe Livre (MPL) tomaram as ruas do Brasil em junho de 2013. 0 êxito dos protestos apartidários liderados pela juventude resultou não só na revogação do reajuste da passagem de ônibus, mas em uma expressão histórica da força da sociedade civil, que demonstrou repúdio a instituições tradicionais como os partidos políticos, as entidades de classe e à própria mídia. A violência cometida pela polícia e por grupos de rebelados provocaram prejuízos para 0 patrimônio público e privado e dezenas de prisões. 0 acontecimento, construído nas redes sociais, foi destacado nos veículos de comunicação do Brasil e de outros países. 
dos polos da produção e da recepção, as teorias de comunicação também enfrentam o desafio de elaborar paradigmas descentrados desses mesmos polos. ${ }^{4}$

Deslocando, porém, o olhar para as potencialidades de mediação dos meios, Martín-Barbero e Rey (2001) propõem uma perspectiva inovadora sobre 0 espaço de natureza simbólica que medeia as interações entre produção e recepção nas negociações de sentidos reorganizadoras da percepção. 0 conceito de mediação supera a bipolaridade ou a dicotomia entre as lógicas das ações da mídia e as dos usos, e implica a constante transformação de significados à medida que textos da mídia e textos sobre a mídia circulam em diferentes formas e que as pessoas colaboram para a sua produção. 0 autor reflete sobre uma crítica capaz de distinguir entre a denúncia da cumplicidade da televisão com os interesses do poder e do mercado e o lugar estratégico que a televisão ocupa na transformação de sensibilidades, na construção de imaginários e identidades. Nota-se que a mediação é dialética e que as tecnologias são moldadas através do consumo e, por sua vez, contribuem para modelar as interações sociais (SILVERSTONE,
2005). E os estudos da produção de sentidos e das relações entre as práticas daqueles que produzem sons, imagens e narrativas e as de quem os recebe contribuem para 0 entendimento da TV como mediação tecnológica e cultural, compreendendo a tecnicidade como um novo regime de visualidade e de significação da experiência. Fiske $(1987,2011)$ afirma, inclusive, que a leitura dos programas de televisão é uma forma de diálogo, o que não significa dizer que os textos televisivos são obras polêmicas. É claro que os programas propõem representações dos acontecimentos em sintonia com os valores e as ideologias dominantes. Mas não se pode deixar de considerar que as negociações de sentidos das audiências não estão enclausuradas no texto, e que são operadas em outras instâncias domésticas e profissionais da vida social para além da(s) tela(s), o que colabora para a polissemia da narrativa televisiva. 0s sentidos das mensagens da televisão também são construídos em outros textos sobre televisão, nas leituras das audiências sobre os programas e em suas próprias interações, as quais não devem ser pensadas apenas como um equilíbrio feliz e harmônico de forças entre o poder ideológico do meio e as interpretações das audiências dos textos da mídia. Uma análise mais ampla desses

Durante muitas décadas, desde o início do século XX prevaleceu a convicção do poder absoluto dos meios sobre 0 comportamento humano e dos veículos de comunicação como propagadores de ideologias que manipulam as consciências. Posteriormente, as teorias da comunicação focalizaram os textos e a compreensão dos produtos midiáticos como fenômenos de cultura. Foram também inseridas nesse debate a noção de alteridade e as relações entre identidade e cultura. Em seguida, passaram a ser ressaltados os efeitos das tecnologias da mídia sobre as sensações e sensibilidades humanas. 0 lugar do receptor somente é destacado a partir das contribuições da escola de Konstanz, chamada de Estética da recepção, considerando que é 0 leitor que dá sentido ao texto, embora sua atuação é sempre guiada a partir das orientações do próprio texto. 
processos exige elucidar as maneiras como são construídos e definidos não só os discursos televisivos, mas a própria recepção em um determinado contexto (BUCKINGHAM, 2010). As atividades do público são complexas, constituem os processos de comunicação e estão inscritas em práticas culturais e sociais associadas ainda a movimentos populares (JACKS; ESCOTEGUY, 2005). Afinal, os textos audiovisuais não devem ser vistos apenas como instrumentos para reproduzir valores e estéticas, estimulando os indivíduos a se identificarem com ideologias dominantes, mas como modos de criar a cultura contemporânea, constituída por sistemas mais ou menos inventivos de representações e combinações entre som e imagem, as quais não têm um sentido fixo (0`DONNELL, 2013).

Os intercâmbios que as audiências têm com notícias que incorporam a linguagem audiovisual e recursos multimídia na televisão, em sites e redes sociais podem ser explorados por meio da metodologia de análise de recepção transmídia proposta por Orozco (2013), que permite identificar tipos e níveis de interatividade, e dos estudos sobre interações mediadas por computador, mais especificamente sobre a circulação e ressignificação de acontecimentos nas redes sociais (PRIMO, 2013; ZAG0, 2012), as quais já esboçam contribuições relevantes para as pesquisas em jornalismo. Mas, há necessidade de um esforço de ampliação do conceito de mediação para uma compreensão maior dos vínculos que se estabelecem entre pessoas e dispositivos técnicos na construção de sentidos sobre os acontecimentos, como as contribuições de Miller (2012) e da Teoria do Ator-Rede (TAR). Miller ressalta que nos estudos de interação é preciso verificar as particularidades e funcionalidades de cada um dos meios, observando como os usuários exploram e significam cada uma das mídias no ambiente comunicativo, nomeando o sistema integrado - no qual cada meio é definido em relação a outra mídia pelos usos dos cidadãos - de polymedia. Latour (2012) sugere que uma realidade não pode ser explicada apenas a partir de seu contexto e que a disputa de interesses é insuficiente para compreender a produção dos fatos. Acredita que os objetos têm um poder de agenciamento e que os não humanos - os artefatos tecnológicos - têm importante participação na construção de qualquer fenômeno social constituído por uma heterogeneidade de redes com determinados padrões que se entrelaçam na construção da experiência. Poder-se-ia supor que a circulação de narrativas jornalísticas audiovisuais se dá por meio de hibridizações e traduções e que a leitura dessas mediações nos permitiria identificar os diferentes "actantes" que interagem na construção das notícias em um contexto informativo. A TAR indica que, nos atuais processos de comunicação, tanto os discursos quanto os dispositivos técnicos são atores relevantes para a compreensão das mediações porque ambos intervêm na produção dos sentidos. 0 conceito de Spreadable Media 
cunhado por Jenkins, Ford e Green (2013) aponta ainda que a maior novidade da paisagem midiática contemporânea é o espalhamento de conteúdos em redes formais e informais por meio de formas de engajamento das audiências, que transcendem ações individuais para atuações coletivas e comunitárias. Os três autores afirmam que as conversações dos cidadãos favorecidas pelas plataformas e redes sociais não resultam na democratização da mídia ou na desestabilização dos modelos de negócios das empresas de comunicação porque 0 tipo de cultura que é produzida e distribuída com essas ferramentas ainda está sendo determinado e não apenas pelas tecnologias digitais. Mas o desejo das audiências de compartilhar conteúdos de acordo com seus interesses estabelece uma forma híbrida de circulação de textos midiáticos, que se movem entre esferas comerciais e não comerciais, $\mathrm{e}$ remodela o fluxo da mídia, atribuindo outros enquadramentos às mensagens. E esta dinâmica de reposicionamento de conteúdos da mídia tende a erodir a divisão entre produção e consumo e a intervir na centralidade de instituições políticas e culturais.

Inspirado nessas perspectivas teóricas, este trabalho apresenta um mapeamento do ambiente midiático onde 0 Jornal Nacional está inserido, identificando os modos como o noticiário se relaciona com as mídias digitais e as audiências, a partir de um estudo quantitativo e qualitativo da produção e do consumo dos formatos e conteúdos noticiosos em áudio e vídeo veiculados pelo telejornal na cobertura dos protestos de junho de 2013 no Brasil. São focalizadas três das quatro etapas que constituem a prática jornalística propostas por Machado e Palacios (2007) - a apuração, a produção, a circulação e o consumo. Foram analisadas as edições do JN de 13 a 22 de junho de 2013, gravadas em DVD, totalizando quase nove horas de material audiovisual. É adotada a metodologia proposta por Becker (2012b) por permitir uma leitura crítica das narrativas jornalísticas audiovisuais, formada por três fases distintas: descrição, análise televisual ${ }^{5} \mathrm{e}$ interpretação dos resultados.

\section{Mapeando a produção e o consumo de notícias}
A partir da análise televisual da cobertura do Jornal Nacional dos Protestos de Junho sistematizada em estudo anterior, foi possível identificar que a insatisfação com a mídia tradicional resultou em mudanças na forma de narrar os acontecimentos de jornais e emissoras de televisão, inclusive da Rede Globo. 
Na cobertura do JN, houve uma flexibilização do formato e um aumento do tempo dos blocos, das matérias e das edições do telejornal, com entradas ao vivo de repórteres de diferentes cidades do país. Cidadãos que participavam pacificamente das manifestações eram valorizados, enquanto os violentos baderneiros eram atacados. Assim, o noticiário encontrou um caminho para tentar mediar a organização simbólica de uma realidade caótica na tela da TV, reafirmando a televisão como a principal arena política na atualidade. Abriu espaço para vozes diferentes manifestarem suas opiniões e até transmitiu a hostilidade de participantes à própria emissora, ação impensável há poucas décadas, assim como as agressivas atitudes de policiais e participantes. Porém, houve situações que comprometeram a cobertura, quando a maioria dos repórteres, ainda que por proteção, passou a entrar ao vivo com informações precárias e previsíveis sobre os Protestos apenas em sobrevoo de helicópteros ou do alto de prédios, próximos à linha editorial do telejornal, mas distantes do acontecimento e das ruas, enquanto a mídia independente no meio da multidão apresentava informações bem mais consistentes e disputava espaços de expressão noticiosa com os meios convencionais. ${ }^{6}$ Mas a mídia eletrônica não deixou de exercer a sua principal vocação de informar e de legitimar 0 Movimento ao expandi-lo para a tela da TV.

Após a análise televisual, foi realizado um mapeamento do ambiente midiático onde 0 Jornal Nacional está inserido e buscou-se identificar as mídias com as quais o telejornal interage, uma informação que os links do portal G1, o portal de notícias das organizações Globo, ${ }^{7}$ onde 0 telejornal está encubado, não oferecem. Mas a utilização de um dos dois aplicativos do noticiário para o celular, o "com vc", que não reproduz conteúdo, mas que direciona para 0 site do G1, 0 Twitter e 0 Facebook do JN, permitiu verificar que estas são as mídias com as quais o noticiário se relaciona diretamente; por essa razão escolhidas para a análise. E para entender como as audiências se apropriam dos conteúdos e formatos noticiosos em áudio e vídeo foram coletados e analisados os depoimentos publicados no Facebook do JN no período estudado.

0 G1 reúne a produção jornalística da Rede Globo, do jornal 0 Globo e a produção do próprio portal. 0 site do Jornal Nacional está encubado no conteúdo do G1, onde é possível acessar reportagens e textos de chamada das matérias enunciados pelos âncoras, veiculados na televisão de cada uma das edições do noticiário. Mas as edições completas do telejornal estão disponíveis

Os Ninjas se destacaram pela descentralização informativa, viabilizando uma cobertura em streaming baseada na contribuição de pessoas com uma mídia móvel sem a editorialização das reportagens televisivas (<http://canalpostv.blogspot.com.br/>). A produção amadorística com grande força de testemunho foi compartilhada por centenas de pessoas. 
apenas para os assinantes da globo.com. A0 acessar o conteúdo disponibilizado na seção "Vídeos", o usuário pode selecionar a data desejada, mas não tem possibilidade de fazer comentários. A única possibilidade de interagir com o conteúdo do telejornal é utilizar a ferramenta disponível para compartilhar, seja por Twitter, Facebook ou Orkut, sendo possível visualizar a quantidade de compartilhamentos de cada vídeo nas redes sociais citadas. ${ }^{8} \mathrm{~A}$ análise quantitativa da produção audiovisual do site do JN no período estudado permitiu apurar que todos os 227 vídeos publicados pelo portal correspondem às reportagens televisivas veiculadas no telejornal, uma média diária de 25 vídeos, e que 139 deles, ou seja, $61 \%$ foram sobre os Protestos de Junho.

Ao inserir "globo jornal nacional" na loja de aplicativos de um smartphone, aparecem duas opções que permitem a visualização de conteúdos do telejornal. 0 aplicativo 9 "globo.tv" permite acessar 0 JN e a programação dos canais da Rede Globo e dos canais Globosat. Ao acessar a página do JN, são oferecidos os VTs (as matérias) que foram ao ar em cada data, assim como no site do G1. É possível visualizar pelo smartphone todas as edições do noticiário. No entanto não há espaço para comentários das audiências, como no G1. A análise dos conteúdos publicados e gravados de 13 a 22 de junho revela que o material audiovisual disponibilizado também foi o mesmo do G1. 0 aplicativo 10 "com vc" permite ao usuário acessar qualquer programa da Rede Globo de sua preferência e visualizar a sinopse do Jornal Nacional e o horário do telejornal. São oferecidas como opções disponíveis: 0 alarme, que notifica no celular que o JN está entrando no ar, a visitação do site do JN no G1, o acesso às contas oficiais do Twitter e do Facebook do noticiário e a possibilidade de convidar amigos para assistir ao telejornal através do compartilhamento por essas plataformas ou por e-mail.

Através de sua conta oficial do Twitter "Jornal Nacional @JNTVGloboBrasil", ${ }^{11}$ o telejornal anuncia as pautas que estarão entrando no ar no horário em que ele é veiculado na televisão. A atualização não é regular e não obedece a um padrão diário. 0 perfil do $\mathrm{JN}$ possui 887.748 seguidores e não compartilha suas publicações ou comentários. No período observado foram feitas quarenta e seis postagens, sendo que entre estas

Elogios, críticas e sugestões à emissora só podem ser enviadas através da seção "Fale Conosco", no link <http:// falecomaredeglobo.globo.com/index1.aspx>, integrada à Central de Atendimento ao Telespectador, por meio de mensagens privadas. 
trinta e três fazem referência às manifestações em todo o Brasil e vinte e duas trazem links ao vivo para assistir ao jornal via internet em streaming . A partir do dia 18 de junho, o @JNTVGloboBrasil passou a utilizar a hashtag "\#cobertura_globo" e incrementou a utilização de sua conta do Twitter com chamadas para acompanhar a cobertura ao vivo na tela da TV. No entanto, entre 13 e 22 de junho o Twitter do JN alcançou apenas 1,3 pontos do Ibope, ${ }^{12}$ bem abaixo da média de audiência televisiva do telejornal, de 35 pontos.

A observação dos conteúdos e formatos em áudio e vídeo publicados no Facebook do JN permitiu verificar como o telejornal se relaciona com esta rede social e como as audiências se apropriaram das notícias veiculadas sobre os protestos por meio de um estudo de seus comentários. 0 Jornal Nacional utiliza a sua página oficial do Facebook $^{13}$ para informar que 0 telejornal está no ar e as notícias de cada edição. Esta é a única mídia em que 0 JN está presente oficialmente, na qual os internautas podem interagir. Com
3.310.932 curtidas, equivalente ao número de pessoas que recebem as postagens, a página não é alimentada regularmente, mas permite a postagem de comentários. 0 número de seguidores do perfil do JN no Facebook no período estudado é mais expressivo do que no Twitter, atingindo 5,1 pontos. ${ }^{14}$ Durante o período analisado foram realizadas duas postagens do telejornal, uma com texto verbal e outra referente às manifestações com link para vídeo em streaming. No dia 18/06 a informação "0 JN está no ar!" recebeu 5.715 curtidas, 825 comentários e 83 compartilhamentos. No dia 20/06 o post "Veja informações da chegada de manifestantes para novos protestos pelo país no Jornal Nacional: http://glo.bo/14MLy14" recebeu 1.159 curtidas, 311 comentários e 56 compartilhamentos. Nos dias dessas postagens foram feitos, portanto, 1.136 comentários. Foi possível recuperar e coletar através de printscreens, como fotografias da tela, armazenar em formato de imagem e classificar oitenta por cento deles, disponíveis na página do JN no Facebook, um total de 914 depoimentos os quais constituíram

120 alcance das mensagens do JN enviadas pelo Twitter é medido através de uma comparação entre o número dos seguidores do Twitter com os pontos de audiência do IBOPE do noticiário na televisão. Com base na atualização de 20/01/2014, 0 valor de um ponto do IBOPE na sua medição de audiência de televisão aberta no Brasil é de 641.286 indivíduos no Painel Nacional de Televisão (PNT). (IBOPE..., 2014)

13 Disponível em: <https://www.facebook.com/JornalNacional>. Acesso em: 13 jan. 2014.

14

0 alcance das mensagens publicadas no Facebook pode ser medido da mesma maneira que no Twitter, por meio de uma comparação entre o número de curtidas ou de pessoas que recebem as postagens dos internautas e os pontos de audiência do IBOPE do JN na televisão.

15 A diferença de 222 depoimentos do número inicial de 1.136 existentes indicado pela rede social foi percebida pelo usuário Cristiano Falk, o qual sugeriu que parte dos comentários possa ter sido censurada e excluída da página. Outra justificativa possível seria a de um erro técnico na contagem do Facebook. 
Quadro 1: Fãs acompanham o funeral em telões públicos

\begin{tabular}{|l|c|c|c|c|c|c|}
\hline $\begin{array}{l}\text { Tipos de } \\
\text { comentários }\end{array}$ & Elogios & Crítica & Humor & $\begin{array}{c}\text { Informações } \\
\text { Complementares }\end{array}$ & Outros & Total \\
\hline $\begin{array}{l}\text { Número de } \\
\text { comentários }\end{array}$ & 117 & 353 & 92 & 133 & 219 & 914 \\
\hline
\end{tabular}

Fonte: Acervo pessoal da autora

uma mostra expressiva para este estudo. ${ }^{15}$

Foram adotadas cinco formas de classificação na análise de cada um dos comentários: Elogios, Crítica, Humor, Informações Complementares à cobertura do noticiário e Outros. Esta última categoria engloba os comentários que não expressavam opinião sobre o próprio telejornal, não adicionavam novas informações ou ajudavam a construir conteúdo. Os resultados da análise foram sistematizados no Quadro 1:

Observa-se que 38\% das pessoas que compartilhavam suas impressões sobre a cobertura do JN na sua página do Facebook a criticaram. Porém, menos de 15\% dos comentários agregaram outras informações às notícias e ao acontecimento. Um exemplo de comentário crítico foi o de Josiel Chaves no dia 18 de junho: "O jornal nacional só passa o que eles querem, e muitos acreditam no que eles falam, a globo é uma emissora que manipula as pessoas. Fora globo", antagônico ao elogio de Francisco Almeida, na mesma data: "PARABÉNS X 10000000! A cobertura das manifestações está maravilhosamente bem colocada. [...] Os dois lados estão sendo respeitados e apresentados de forma pacífica e democrática. [...]." 0 comentário de Edione

Cintia dos Santos em 20 de junho é um exemplo dos depoimentos que atribuíram novas informações à cobertura: "Em carapicuiba esta acontecendo uma manifestação e esta conseguindo atingir as cidades Osasco. Barueri. Jandira Itapevi e sentido a Sorocaba. Pq esta parando a castelo branco". Os comentários classificados como humor não despertaram intervenções inspiradoras sobre os relatos do telejornal, como o de Ana Paula Rodrigues em 18 de junho: "liga pra fatima assistir vc boner!kk...k". Na categoria Outros os comentários se restringiram a breves depoimentos, como o de Rafael Murakami em 20 de junho: "FORA CORRUPTOS" ou o de Cielly Cris no dia 18: "Já estou assistindo".

Este estudo revela que o telejornal tende a se expandir por distintos veículos e canais, distribuindo o mesmo conteúdo e formato em áudio e vídeo e/ou com pequenas adaptações editoriais, nomeadas de práticas de shovelware e de repurposing por McCombs (2009) e Salaverría e Negredo (2008), o que não colabora para a qualidade do jornalismo audiovisual. Assim, observou-se como as 139 matérias veiculadas 
pelo JN foram integralmente disponibilizadas no G1 e para os smartphones, por meio dos aplicativos, sem que estas mídias tenham produzido qualquer vídeo original no período estudado. Todos os áudios e vídeos publicados seguiram características da linguagem do telejornal. No Facebook do JN só houve duas postagens em vídeo do próprio noticiário, uma sobre os Protestos. A participação dos usuários foi por meio da publicação de comentários verbais. No Twitter, também se observou que a maioria das postagens foi formada apenas por palavras, porém a maior parte delas sobre 0 acontecimento apresentou links ao vivo para assistir ao Jornal via internet em streaming. As apropriações das tecnologias digitais oferecem uma ampliação da participação dos usuários e um intercâmbio entre os distintos públicos. No entanto, os comentários analisados do Facebook do JN tampouco colaboraram para a diversidade da cobertura. As audiências debateram entre si e tentaram construir um diálogo com o telejornal sem resposta direta. Contudo, verifica-se que fora dos canais convencionais das grandes empresas as audiências tendem a romper a formatação e a hierarquização dos conteúdos audiovisuais noticiosos dos canais convencionais por meio da produção descentralizada de outras narrativas, como a produção digital do movimento Ninja sobre os Protestos de junho, que chegou a alcançar picos de audiência de 120 mil espectadores, correspondentes a 1,2 pontos do Ibope

(LORENZOTTI, 2013), ainda que esse número seja pouco expressivo se comparado aos oito milhões de telespectadores que assistiram ao JN no período estudado. ${ }^{16}$

\section{Considerações finais}

Se a narrativa polifônica propõe uma réplica e nessa atitude responsiva reside a construção do sentido pelos interlocutores que manifestam diferentes pontos de vista sem apresentação de uma verdade acabada (BAKHTIN, 2006), o diálogo televisual implicaria uma forma de comunicação na qual as pessoas poderiam intervir no processo de produção noticiosa por meio da criação de conteúdos e formatos audiovisuais. Porém, não se pode afirmar que o jornalismo audiovisual é uma narrativa dialógica na concepção bakhtiniana porque 0 acúmulo de informações nem sempre resulta na construção de informações mais plurais do cotidiano social em áudio e vídeo no ambiente midiático onde 0 telejornal está inserido, prevalecendo discursos dominantes ou reduntantes. É certo que as audiências já podem realizar uma associação ativa de ligações transversais entre informações disponíveis e armazenadas diante das telas e criar uma pluralidade de significações das notícias. Mas a autonomia dos cidadãos também é cercada por limitações derivadas de convenções e hábitos que 
caracterizam as práticas de leituras (CHARTIER, 1998), inclusive de vídeos por meio dos quais 0 conhecimento circula na atualidade Assim, foi possível observar que a atuação dos cidadãos ainda está restrita ao papel de intérpretes do acontecimento na interação com os noticiários televisivos. Os usos das tecnologias digitais favorecem a ressignificação das narrativas jornalísticas audiovisuais, o deslocamento do receptor para o lugar de produtor e tecem novas formas de vínculos e identidades entre produção e recepção. Porém, as audiências ainda não intervêm de maneira expressiva nos modos como as notícias televisivas são construídas. A inclusão da opinião de telespectadores e usuários ainda parte da crítica, da mistura e da reciclagem de textos do próprio telejornal. A análise dos modos como as notícias são produzidas, circulam e são consumidas, revela que tanto a retroalimentação de conteúdos e formatos entre as diferentes mídias quanto as atuais possibilidades de interação das audiências têm assegurado ao noticiário sua expansão como gênero informativo na era da convergência por meio de telas distintas e seu protagonismo nas enunciações dos acontecimentos. De fato, comparando-se os 35 pontos de audiência do JN na televisão, no período estudado, com as visualizações ou seguidores das redes sociais que têm acesso ao seu conteúdo, verifica-se que os 5,1 pontos de audiência do Facebook e o 1,3 ponto do Twitter são pouco expressivos. Não foi possível realizar essa média do G1 e dos aplicativos para celular, pois nestas mídias não estão expostos os números de visualizações de cada conteúdo.

No entanto, este estudo também mostra a tendência das audiências de ressignificarem não apenas as narrativas jornalísticas audiovisuais, mas a centralidade da própria mídia em suas conversações por meio de processos de interação ainda em transformação entre as pessoas, a televisão e o computador. Até mesmo as pesquisas quantitativas de audiência que utilizam métricas como indicadores de perfomances das mídias, apenas recentemente passaram a utilizar ferramentas que permitem acompanhar como cidadãos e mensagens audiovisuais se movem simutaneamente na TV e em dispositivos e plataformas digitais. ${ }^{17} \mathrm{~A}$ compreensão dos atuais e complexos processos de mediação demanda um olhar para o conjunto das mídias como um ambiente comunicativo e indica a necessidade de estudos contínuos que possam capturar e descrever a heterogeneidade de mudanças gerada pela mídia com as sociedades porque os discursos dos meios não eliminam a busca crítica e criativa de sentidos e da experiência.

\section{Referências}

BECKER, B. Convergência x Diversidade: repensando a qualidade das notícias na TV. Brazilian Journalism 
Research, Rio de Janeiro, v. 8, n. 2, 2012a. Disponível em: <http://bjr.sbpjor.org.br/bjr/article/view/416>. Acesso em: 14 de fevereiro de 2014.

BECKER, B. Mídia e Jornalismo como formas de conhecimento: uma metodologia para leitura crítica das narrativas jornalísticas audiovisuais. Matrizes: Revista do Programa de Pós-Graduação em Ciências da Comunicação da Universidade de São Paulo, São Paulo, v. 5, n. $2,2012 b$.

BECKER, B. Jornalismo audiovisual de qualidade: um conceito em construção. Estudos em jornalismo e mídia, v. 6, n. 2, 2009. Disponível em: < http://www. periodicos.ufsc.br/index.php/jornalismo/article/ view/11336 > . Acesso em: 13 fev. 2014.

BECKER, B. A linguagem do telejornal: um Estudo da Cobertura dos 500 Anos do Descobrimento do Brasil. Rio de Janeiro: E-papers, 2005.

BAKHTIN, M. Problemas da poética de Dostoiévski. 3. ed. Rio de Janeiro:Forense Universitária, 2002.

BAKHTIN, M. Estética da criação verbal. São Paulo: Martins Fontes, 2006.

BUCKINGHAM, D. A Especial Audience? Children and Television. In: WASKO, Janet (Ed.). A companion to

Television. United Kingdom: Wiley-Blackwell, 2010.

CHARTIER, R. A aventura do livro: do leitor ao navegador. São Paulo: UNESP, 1998.

FISKE, John. Television culture. London: Routledge, 2011.

IB0PE reajusta valor do ponto de audiência. 2014. Disponível em: < http://exame.abril.com.br/tecnologia/ noticias/ibope-reajusta-valor-do-ponto-de-audiencia $>$. Acesso em: 12 jan. 2014.

JACKS, N.; ESCOSTEGUY, A. C. Comunicação e recepção. São Paulo: Hacker Editora, 2005.

JENKINS, H.; FORD, S.; GREEN, J. Spreadble Media, creating value and meaning in a networked culture.
New York: New York University Press, 2013.

LATOUR, B. Reagregando o social: uma introdução à Teoria do Ator-Rede. Salvador: Edufba, 2012.

LORENZOTTI, E. POSTV, de pós-jornalistas para pós-telespectadores. 2013. Disponível em: < http:// www.observatoriodaimprensa.com.br/news/view/postv_ de_pos_jornalistas_para_pos_telespectadores $>$

MACHAD0, A. Fim da televisão? Revista FAMECOS, Porto Alegre, v. 18, n. 1, jan./abr. 2011.

MACHAD0, A. Miséria do dialogismo. In: MACHAD0, A. Os anos de chumbo: mídia, poética e ideologia no período de resistência ao autoritarismo militar (19681985). Porto Alegre: Sulina, 2006.

MACHAD0, E.; PALACIOS, M. Um modelo híbrido de pesquisa: a metodologia aplicada pelo GJOL. In: LAG0, C.; BENETTI, M. (Org.). Metodogia de pesquisa em jornalismo. Petrópolis, RJ: Vozes, 2007. p. 199-222.

McCOMBS, M. A teoria da agenda: a mídia e a opinião pública. Petrópolis, RJ: Vozes, 2009.

MARTÍN-BARBERO, J.; REY, G. Os exercícios do ver: hegemonia audiovisual e ficção televisiva. São Paulo: SENAC São Paulo, 2001.

MILLER, D. Migration and New Media: transnational families and polymedia. London: Paperback, 2012.

0’DONNELL, V. Television Criticism. Thousand Oaks: Sage Publications, 2013.

OROZC0, G. Las audiencias convergentes y su investigación: análisis de la recepción transmedial de la serie El Equipo. Comunicação \& Sociedade. São Paulo, v. 34, n. 2, 2013. Disponível em: < https://www. metodista.br/revistas/revistas-metodista/index.php/ CSO/article/view/3682 >. Acesso em: 11 nov. 2013.

PRIMO, A. (Org.). Interações em rede. Porto Alegre: Sulina, 2013.

REDE GLOBO. Direção Geral de Comercialização. Audiência e perfil. [2007]. Disponível em: < http:// 
comercial.redeglobo.com.br/programacao_jornalismo/ jnac5_ap.php >. Acesso em: 20 jan. 2014.

SALAVERRÍA, R.; NEGREDO, S. Periodismo

integrado: convergencia de medios y reorganización de redacciones. Barcelona: Editorial Sol90 Media, 2008.

SCOLARI, C. A. Ecología de la hipertelevisión. Complejidad narrativa, simulación y trasmedialidad en la televisión contemporánea. In: SQUIRRA, S.; FECHINE, Y. (Org.). Televisão Digital: desafios para a comunicação. Porto Alegre: Sulina, 2009.

SILVERSTONE, R. Por que estudar a mídia? São Paulo: Edições Loyola, 2005.

RODRÍGUEZ, J. J. V.; DÍAZ-GONZÁLEZ, M.; TORRE, M. G. Contenidos periodísticos audiovisuales en aplicaciones móviles de televisión. In: CANAVILHAS, J. (Org.). Notícias e mobilidade: jornalismo na era dos dispositivos móveis. Beira Interior, Portugal: Labcom Books, 2013. Disponível em: < http://www.livroslabcom. ubi.pt/pdfs/20130404-201301_joaocanavilha_ noticiasmobilidade.pdf > . Acesso em: 10 out. 2013.

VILCHES, L. Television digital: entre la esperanza y el exceptismo. In: SQUIRRA, S.; FECHINE, Y. (Org.).

Televisão digital: desafios para a comunicação. Porto Alegre: Sulina, 2009.

ZAGO, G. Da circulação à Recirculação Jornalística: filtro e comentário de notícias por interagentes no Twitter. In: ENCONTRO ANUAL DA COMPÓS, 21., 2012. Juiz de Fora. Anais... Juiz de Fora: Compós, 2012. Disponível em: < https://dl.dropboxusercontent. com/u/2757182/artigos/zagocompos2012.pdf $>$. Acesso em: 12 dez. 2013. 
Television and new media: rethinking the role of audiences on TV News

\section{Abstract}

This article seeks to identify the interactions between television and the internet in the media environment where Jornal Nacional is inserted, check the current language characteristics of the audiovisual journalistic narratives and understand how the relations with the public are established in the experience of participatory culture enhanced by convergence, from the televisual analysis of the coverage of the June Protests ( in Brazil) of the country's wider audience TV News. It is supported by the contributions of the theories of communication and based on journalism studies and reception.

\section{Keywords}

Television. Broadcast Journalism. Internet. Audiences. Jornal Nacional.

\section{Televisión y nuevos medios: repensar el papel de las audiencias en los noticieros}

\section{Resumen}

Este artículo trata de identificar las interacciones entre la televisión e Internet en el entorno de los medios de comunicación donde se inserta el Jornal Nacional, revisar las actuales características del lenguaje de narrativas audiovisuales periodísticas y entender cómo se establecen las relaciones con el público en la experiencia de la cultura participativa potenciada por la convergencia, a partir del análisis televisivo de la cobertura de las protestas de junio( en Brasil) de noticiero del más grande audiencia del país. Se basa en las contribuciones de las teorías de la comunicación y de los estudios de periodismo y recepción.

\section{Palabras-Clave}

Televisión. Periodismo televisivo. Internet. Audiencias. Jornal Nacional. 


\section{Expediente}

A revista E-Compós é a publicação científica em formato eletrônico da Associação Nacional dos Programas de Pós-Graduação em Comunicação (Compós). Lançada em 2004, tem como principal finalidade difundir a produção acadêmica de pesquisadores da área de Comunicação, inseridos em instituições do Brasil e do exterior.

\section{E-COMPÓS I www.e-compos.org.br I E-ISSN 1808-2599}

Revista da Associação Nacional dos Programas

de Pós-Graduação em Comunicacão.

Brasília, v.17, n.2, mai./ago. 2014.

A identificação das edições, a partir de 2008

passa a ser volume anual com três números.

\section{CONSELHO EDITORIAL}

Afonso Albuquerque, Universidade Federal Fluminense, Brasil Alberto Carlos Augusto Klein, Universidade Estadual de Londrina, Brasil Alex Fernando Teixeira Primo, Universidade Federal do Rio Grande do Sul, Brasil Rio Grande do Sul, Brasi

Ana Gruszynski, Universidade Federal do Rio Grande do Sul, Brasil Ana Silvia Lopes Davi Médola, Universidade Estadual Paulista, Brasil André Luiz Martins Lemos, Universidade Federal da Bahia, Brasi Ângela Freire Prysthon, Universidade Federal de Pernambuco, Brasil Antônio Fausto Neto, Universidade do Vale do Rio dos Sinos, Brasil Antonio Carlos Hohlfeldt, Pontifícia Universidade Católica do Rio Grande do Sul, Brasil Antonio Roberto Chiachiri Filho, Faculdade Cásper Líbero, Brasi Arlindo Ribeiro Machado, Universidade de São Paulo, Brasil Arthur Autran Franco de Sá Neto, Universidade Federal de São Carlos, Brasil Benjamim Picado, Universidade Federal Fluminense, Brasil César Geraldo Guimarães, Universidade Federal de Minas Gerais, Brasil Cristiane Freitas Gutfreind, Pontifícia Universidade Católica do Rio Grande do Sul, Brasil Denilson Lopes, Universidade Federal do Rio de Janeiro, Brasil Denize Correa Araujo, Universidade Tuiuti do Paraná, Brasi Edilson Cazeloto, Universidade Paulista , Brasil

Eduardo Vicente, Universidade de São Paulo, Brasil Eneus Trindade, Universidade de São Paulo, Brasil Erick Felinto de Oliveira, Universidade do Estado do Rio de Janeiro, Brasi Florence Dravet, Universidade Católica de Brasília, Brasil Gelson Santana, Universidade Anhembi/Morumbi, Brasi Gilson Vieira Monteiro, Universidade Federal do Amazonas, Brasil Gislene da Silva, Universidade Federal de Santa Catarina, Brasil Guillermo Orozco Gómez, Universidad de Guadalajara Gustavo Daudt Fischer, Universidade do Vale do Rio dos Sinos, Brasil Hector Ospina, Universidad de Manizales, Colômbia Herom Vargas, Universidade Municipal de São Caetano do Sul, Brasil Ieda Tucherman, Universidade Federal do Rio de Janeiro, Brasil Inês Vitorino, Universidade Federal do Ceará, Brasil Janice Caiafa, Universidade Federal do Rio de Janeiro, Brasil Jay David Bolter, Georgia Institute of Technology Jeder Silveira Janotti Junior, Universidade Federal de Pernambuco, Brasi João Freire Filho, Universidade Federal do Rio de Janeiro, Brasil John DH Downing, University of Texas at Austin, Estados Unidos Ana Carolina Damboriarena Escosteguy, Pontifícia Universidade Católica do

José Afonso da Silva Junior, Universidade Federal de Pernambuco, Brasil José Carlos Rodrigues, Pontifícia Universidade Católica do Rio de Janeiro, Brasil José Luiz Aidar Prado, Pontifícia Universidade Católica de São Paulo, Brasil José Luiz Warren Jardim Gomes Braga, Universidade do Vale do Rio dos Sinos, Brasil Juremir Machado da Silva, Pontifícia Universidade Católica do Rio Grande do Sul, Brasil Laan Mendes Barros, Universidade Metodista de São Paulo, Brasil Lance Strate, Fordham University, USA, Estados Unidos Lorraine Leu, University of Bristol, Grã-Bretanha Lucia Leão, Pontifícia Universidade Católica de São Paulo, Brasil Luciana Panke, Universidade Federal do Paraná, Brasil Luiz Claudio Martino, Universidade de Brasília, Brasil Malena Segura Contrera, Universidade Paulista, Brasil Márcio de Vasconcellos Serelle, Pontifícia Universidade Católica de Minas Gerais, Brasil Maria Aparecida Baccega, Universidade de São Paulo e Escola Superior de Propaganda e Marketing, Brasil Maria das Graças Pinto Coelho, Universidade Federal do Rio Grande do Norte, Brasil Maria Immacolata Vassallo de Lopes, Universidade de São Paulo, Brasil Maria Luiza Martins de Mendonça, Universidade Federal de Goiás, Brasil Mauro de Souza Ventura, Universidade Estadual Paulista, Brasil Mauro Pereira Porto, Tulane University, Estados Unidos Nilda Aparecida Jacks, Universidade Federal do Rio Grande do Sul, Brasil Paulo Roberto Gibaldi Vaz, Universidade Federal do Rio de Janeiro, Brasil Potiguara Mendes Silveira Jr, Universidade Federal de Juiz de Fora, Brasil Renato Cordeiro Gomes, Pontifícia Universidade Católica do Rio de Janeiro, Brasil Robert K Logan, University of Toronto, Canadá

Ronaldo George Helal, Universidade do Estado do Rio de Janeiro, Brasil Rosana de Lima Soares, Universidade de São Paulo, Brasi Rose Melo Rocha, Escola Superior de Propaganda e Marketing, Brasil Rossana Reguillo, Instituto de Estudos Superiores do Ocidente, Mexico Rousiley Celi Moreira Maia, Universidade Federal de Minas Gerais, Brasi Sebastião Carlos de Morais Squirra, Universidade Metodista de São Paulo, Brasil Sebastião Guilherme Albano da Costa, Universidade Federal do Rio Grande do Norte, Brasil

Simone Maria Andrade Pereira de Sá, Universidade Federal Fluminense, Brasi Tiago Quiroga Fausto Neto, Universidade de Brasília, Brasil Suzete Venturelli, Universidade de Brasília, Brasil Valerio Fuenzalida Fernández, Puc-Chile, Chile Veneza Mayora Ronsini, Universidade Federal de Santa Maria, Brasil Vera Regina Veiga França, Universidade Federal de Minas Gerais, Brasil

\section{COMISSÃO EDITORIAL}

Cristiane Freitas Gutfreind I Pontifícia Universidade Católica do Rio Grande do Sul, Brasil Irene Machado I Universidade de São Paulo, Brasil

Jorge Cardoso Filho I Universidade Federal do Reconcavo da Bahia, Brasil / Universidade Federal da Bahia, Brasil

CONSULTORES AD HOC

Adriana Amaral, Universidade do Vale do Rio dos Sinos, Brasil

Alexandre Rocha da Silva, Universidade Federal do Rio Grande do Sul, Brasi Arthur Ituassu, Pontifícia Universidade Católica do Rio de Janeiro, Brasil Bruno Souza Leal, Universidade Federal de Minas Gerais, Brasil Elizabeth Bastos Duarte, Universidade Federal de Santa Maria, Brasil Francisco Paulo Jamil Marques, Universidade Federal do Ceará, Brasi Maurício Lissovsky, Universidade Federal do Rio de Janeiro, Brasil Suzana Kilpp, Universidade do Vale do Rio dos Sinos, Brasil Vander Casaqui, Escola Superior de Propaganda e Marketing, Brasil

EDIÇÃO DE TEXTO E RESUMOS I Susane Barros SECRETÁRIA EXECUTIVA I Helena Stigger EDITORAÇÃo ELETRÔNICA I Roka Estúdio
COMPÓS I www.compos.org.br

Associação Nacional dos Programas de Pós-Graduação em Comunicação

Presidente

Eduardo Morettin

Universidade de São Paulo, Brasil

eduardomorettin@usp.br

Vice-presidente

Inês Vitorino

Universidade Federal do Ceará, Brasil

ines@ufc.br

Secretária-Geral

Gislene da Silva

Universidade Federal de Santa Catarina, Brasil

gislenedasilva@gmail.com 